\title{
Effect of Process Parameters on Roughness and Hardness of Surface and Dimensional Accuracy of Lost Wax Process Casting
}

Bihari AK*, Ramachandran M and Kumar V

MPSTME, SVKM'S Narsee Monjee Institute of Management Studies, Shirpur, Dhule 425405, Maharashtra, India

\begin{abstract}
We know different casting processes like sand casting, gravity die casting, low pressure die casting, pressure die casting, counter pressure die casting, and centrifugal casting, spin casting, lost wax and lost foam casting. But lost wax or lost foam casting process are going to be most acceptable way of castings to get the intricate and complex shaped castings. Lost wax process is generally known as "Investment casting process". About 5000 years ago the Egyptians used this process in the time of Pharaohs to make gold jewellery, which was the way of their investment hence the names comes. Ancient "lost wax process" domination for producing beautiful sculptures turns into a present day near net shape manufacturing of intricate engineering components. The journey begins with the development of Investment casting process by Dr. William $\mathrm{H}$. Taggart of Chicago who wrote a detailed study on Investment casting process in 1907. Today's Investment casting is a versatile process. It is used to manufacture parts ranging from turbocharger wheels to golf stick heads, from electronic boxes to hip replacement implants, General engineering to aerospace, automobiles to pump industries particularly impellers. In this paper we are discussing about the key parameters of the investment casting process which will give a more dimensional accuracy and best surface smoothness and hardness for the mold. The pre-conditions for the mold are discussed and possible defects can occur in the mold and the rectification also analysed experimentally.
\end{abstract}

Keywords: Casting; Product defect; Quality assurance

\section{Introduction}

The Investment casting which is also called as lost wax process used for the production of metals castings using wax in the foundry shop. The term investment casting derives from the characteristics use of mobile ceramic slurry to form a mould with extremely smooth surface qualities. Many intricate and more important components in mechanical industries, civil industries and other key industries are manufactured by the investment casting process [1]. The investment casting components are broadly classified into two categories: the first one is conventionally Investment casting and the second one is directionally solidified Investment casting. Conventionally Investment casting components involve the use of a stationary mold and furnace, have equiaxed grains, and are generally used as structural components. Directionally solidified Investment casting castings often employ a mold withdrawal technique and can also be of two types; columnar grained directionally solidified Investment casting castings and single crystal directionally solidified Investment casting castings. Often these components are made of expensive super alloys, are of complex shapes, and vary greatly in size. The literature review shows that lots of other developments of ceramic materials have currently been implemented to explore possible methods for the improvement of shell performance and also lot of research work has been reported on advancement in shell moulding for investment casting. But very less work has been reported on dimensional accuracy of cast component on the effect of various parameters of the investment castings.

So in the present work it is proposed to study the dimensional accuracy of cast component prepared by investment casting process. Investment casting process is always preferred in order to produce extremely good surface quality and with close tolerance. Therefore, investment casting has occupied a key position in the range of modern metal casting techniques [2].

\section{Identification of Critical and Vital Parameters}

For preparing a best investment casting mould, we have to identify the critical and vital parameters of the investment castings. Those critical and vital parameters should satisfy the customer's needs and also it should give major importance for the total quality of the product. The investment castings critical and vital parameters for the products requirements were distinguished on the basis of customer specifications are essentially of three types:

- Dimensional specifications.

- Visual Specifications.

- Metallurgical specifications.

For achieving the above specifications there are series of parameter have to be considered like shrinkage or contraction allowance for die tool making, composition of wax, inject tank temperature and block temperature for the moulding machine, cooling time for the wax pattern, primary coating and secondary coating composition, viscosity factor of the coating and shell firing temperature [3].

These parameters are the main key parameters consider the quality of the investment castings. On the other hand, the key parameters that need to better monitor and control in order to avoid detrimental impacts on equal parts will be identified. In this paper we are experimentally figure out the values ranges for all the critical and vital parameters of the investment castings to get the dimensional, visual and metallurgical specification accuracy for the mould.

*Corresponding author: Bihari AK, MPSTME, SVKM'S Narsee Monjee Institute of Management Studies, Shirpur, Dhule 425405, Maharashtra, India, Tel: 0224235 5555; E-mail: kumar.aakash1508@gmail.com

Received May 14, 2015; Accepted May 27, 2015; Published June 12, 2015

Citation: Bihari AK, Ramachandran M, Kumar V (2015) Effect of Process Parameters on Roughness and Hardness of Surface and Dimensional Accuracy of Lost Wax Process Casting. J Material Sci Eng 4: 175. doi:10.4172/21690022.1000175

Copyright: ( 2015 Bihari AK, et al. This is an open-access article distributed under the terms of the Creative Commons Attribution License, which permits unrestricted use, distribution, and reproduction in any medium, provided the original author and source are credited. 
Citation: Bihari AK, Ramachandran M, Kumar V (2015) Effect of Process Parameters on Roughness and Hardness of Surface and Dimensional Accuracy of Lost Wax Process Casting. J Material Sci Eng 4: 175. doi:10.4172/2169-0022.1000175

\section{Manufacturing process}

The investment casting production process is a mix of handwork, semiautomatic and control operations, it can be divided in the following main steps: The production process consists of an initial phase of injection of "models" of wax components which, when assembled in clusters, are then covered in shell area with refractory ceramic materials that can withstand at high temperatures. The wax is removed and the ceramic shell is sintered. At this step it becomes ready to receive the metal pouring during the cast phase.

Both dimensional and metallurgical problems are joined with the wax pattern production and related operations. The first are due to dimensional deformations could be occur on the parts as a function of the temperature and the extraction times of the wax patterns from the die; also the environmental conditions could affect the dimensional behaviour of the (alloy) parts. Both dimensional and metallurgical problems are joined with the casting processes. The first are due to the dimensional deformations/distortions of the shell during the sintering or casting process, due to the strength of the shell. Other metallurgical problems can be related to permeability, Ceramic inclusions, Alloy melt, Thermal gradients or its distribution not optimized during the pouring and solidification steps. The experiments are conducted in accordance to Taguchi L9 orthogonal array. To make it easy systematic presentation of the process flow is shown below [4].

\section{Die tool making}

For any product which has to casted in investment casting its die has to make first. Usually the material which is taken for die making is aluminium. Add up contraction allowance from die to wax pattern in addition to normal shrinkage/contraction allowance of metal. Generally for steel we take $0.8 \%$ for die to wax and $2.2 \%$ from wax to casting [5].

\section{Wax preparation}

Pattern wax is blend of different types of waxes like, Paraffin, Rosin Gum, Carnova or lignite wax, Polystyrene or LDP (Micro wax). We take these waxes in a certain percentage of each and heat it at about 120 degree Celsius and blend them together.

The best composition for preparation of conditioning wax for the investment casting is given below:

1. Paraffin- $7 \mathrm{~kg}$

2. Rosin gum $-7 \mathrm{~kg}$

3. Lignite- $6 \mathrm{~kg}$

4. Microwax- $1 \mathrm{~kg}$

Total - 21 kgs!

(Tank capacity of Mod Tech is $42 \mathrm{~kg}$ so you can just double the above quantities)

This wax is then poured into the pouring tank of wax moulding machine. This wax can be poured into the die either horizontally or vertically (Horizontal wax moulding machine and Vertical moulding machine).

In Horizontal moulding machine its: we should keep the temperatures difference for the Inject Tank temperature for the moulding machine is from 54 to 59 degree Celsius and the block temperature of the moulding machine is from 53 to 58 degree Celsius. In the vertical moulding machine its: we should keep the temperatures difference for the Inject Tank temperature for the moulding machine is from 65 to 69 degree Celsius and the block temperature of the moulding machine is from 54 to 59 degree Celsius [6].

\section{Cooling time}

Cooling time of the wax pattern depends on its size of the investment casting. For the small component (6 inches) it is usually 60 second and for the big components (above 8 inches) it will take usually 3 to 4 minutes. After cooling then wax pattern is repaired using Micro wax in which diesel is also mixed for ease. Repairing is done so as to remove minuet defects or small holes. After all this waxing process the mould is allowed to cool. Room temperature of Mould cooling- $19-21^{\circ} \mathrm{C}$ [7].

\section{Pattern production}

In this process we inject conditioned wax into dies through injection machine. Pattern is the starting point of production. The final casting can be as good as the wax pattern produced. Whenever core cannot be eliminated by sectioning the patterns then pre formed ceramic or water soluble core are used to give precision internal cavities in the casting and these cores are located in the wax die prior to injection or into a pre-formed cavity in a wax pattern [8].

\section{Pattern assembly}

In pattern assembly we mount the wax patterns into a big wax rod called as runner. About 5 to 6 wax patterns are connected in incline position with the help of sprue and gate. It is also called as tree making [9].

\section{Ceramic shell building}

Ceramic shell is made from refractory materials. It is made to handle the high temperature of molten metal and it also helps in avoiding expansion. Quality and surface finish of any material depends mostly on the type, amount and quality of coating. There are two types of coating namely as Primary coating and secondary coating. Primary coating helps to with stand the temperature of molten metal and second help to separate castings from refractory, improves surface finish. There is a factor which determines the thickness of the slurry ie. Viscosity factor $[10,11]$. It varies for different product depending upon their Shape, size and complexity. Primary coating is a blend of different refractory materials like:

1. Zircon flour grade [-325]

2. Colloidal silica [30\%]

3. Lisa foam

4. 2-ethylhexanol

5. $100 \mathrm{ml}$ of distilled water

6. Lisa foam helps to stick with wax pattern.

7. 2-ethylhexanol is used for removing foam.

Generally the viscosity of primary coating is kept $60-80$ seconds and 90-120 seconds in B-cup. For intricate castings we should go for 60-80 seconds viscosity. Secondary coating contains fine refractory material:

1. Kainite or, molochite (-200 mesh) (smaller particles)

2. Colloidal silica

3. Distilled water

Grade- 50/80; 30/80; 16/30 


\section{Process for primary coating}

We first dip the tree into the primary coating of viscosity $60-80$ then cover it with zircon sand and then set it to dry. When the first coating gets dried up then second coating is followed up the same way as first. After this primary coating, it is allowed to dry up sufficiently for $8 \mathrm{hrs}$. And then tree is taken for secondary coating [12].

\section{Process for secondary coating}

For secondary coating viscosity is $17-20$ seconds. We dip the tree into the secondary coating and then cover it up with molochite grains of grade 50/80 twice and then dip it into the secondary slurry and allow it to become dry. After dry give two coat of $30 / 80$ and again dip it and dry it. Now give layer of $16 / 30$ and after dry it dip it in the secondary slurry few times. Give sufficient time in between two coats of minimum 8-12 hrs in controlled drying room with 20-22 degree $\mathrm{C}$ temperature and $55-60 \%$ humidity. The above temperature and humidity helps to dry the shell quickly without wax expansion and contraction. Air circulation helps to dry the shell quickly. The process of dipping the pattern tree, drain, and coat with refractory sand repeats with different fineness of sand for 7-8 times. Finally dry the shell for $48 \mathrm{hrs}$ before de-waxing.

\section{De waxing}

Dried shell can be de-waxed mostly by dipping into the molten wax. Steam autoclave, dry hot air is also used for dewaxing. Dewaxing by the use of microwave has been achieved in the past 10 years in advance countries. Shell that is not fully dried prior to dewax or not have achieved sufficient strength to withstand the internal pressure of the expanding wax results in crack. Dried shell is dipped into molten wax which is at temperature about $150^{\circ} \mathrm{C}$ this will lead to de-waxing ie. wax in the shell will easily melt and slip from shell opening [13].

\section{Shell firing}

Shell baking or firing helps to build the hot strength of the mould and it remove the residual waxes. Finally the firing and the shell required temperature depends on the metal to be poured. Aluminium castings are poured at $300-400$ degree $\mathrm{C}$, Bronze at 500 to $600^{\circ} \mathrm{C}$, Steel is typically poured at 900-1000 degree C. But do remember that all the shell should be fired at 1000 degree $\mathrm{C}$ and hold for an hour above certain temperature. For specified material pouring temperature is different. It means if, we are going to cast Aluminium then heat up first at 1000 degree $\mathrm{C}$ and hold it for an hr. And before pouring the molten metal (Aluminium) bring down the shell temp. At around 300-400 degree C. Firing or pre heating are normally carried out in box type shell baking furnace or muffle furnace. So depending upon the material which has to be poured the shell is heated so that it can handle the temperature of the molten material during pouring. Now a days CNG fired shell baking furnaces are also being used to reduce the fuel cost.

\section{Melting /Pouring}

Generally Induction melting is used because of its flexibility of making wide range of alloys and makes it faster and being more efficient process than another conventional melting. After the shell has been baked and it has achieved the desired temperature for pouring it is then kept on thick sand surface so as to make it stand still. After that molten metal is poured into the shell and allowed to cool.

\section{Cleaning/ fettling}

Once metal is poured and cooled down it is then we remove skulls of refractoriness material with vibrator and separate the castings from the runner with general process of gate cutting. Vibrator produces very high power of rigorous vibrations which detaches the refractory material coat from the metal. For the fast production of steel castings generally air plasma is used. Once the castings are separated we clean it with sand / shot blasting and grind it like conventional process.

\section{Product Quality Assurance}

The investment castings can go for a series of testing for the quality assurance for determing the dimensional accuracy of the casting, surface hardness of the casting and surface smoothness of the casting. Where the testing are carried out to identified the critical parameters of the investment castings. The following are the basic testing's to find the dimensional quality of the investment castings which is usually a non destructive testing methodology [14].

Coordinate measuring machine is used to measure the parts in specific points to guarantee the geometrical integrity of the investment casting. The tolerance is allowed up to $0.01 \mathrm{~mm}$ for the casting products.

Gauge is usually used for the small casting parts to measure the parts in specific points a wide range of variables, consequence of heterogeneous materials and of a large variety of processes involved in the investment casting operations. The product defects are divided in two different macro areas on the basis of their impact on company costs: precast defect (During mould making) and post cast (during casting) defect. Each macro area can generate specific defects on the parts, which origin can be summarized as follows.

The Precast defect can arise from the following two different conditions one at the wax room and another at the shell room. In the wax room the precast defect can occur due to the core breakage or shifting during the injection of wax or by means of the wax depletion and some cases human imperfection while carry out the casting process. In shell room the role of the thickness and strength of the shell can create the precast defect in the investment castings. This kind of defect can be reduced by using the modern techniques in the injection of wax and determining the proper thickness and the strength of the shell for the investment casting process.

During cast defect can arise from the two different condition, the first one is due to melting process like high molten temperature, second Degassing of molten metal. Pyrometer helps to control temperature of molten metal and proper degasser like calcium silicide, aluminium shots helps in Stainless steel or argon purging helps in degassing. These both post cast defect can be avoided by means of proper controlling of melting process [15].

\section{Conclusions}

Identification of the critical and vital parameters of the investment castings will lead to a lower production cost, better quality and increased competitiveness. Emphasis on the production of near net shape components has further stimulated the growth of the investment casting industry in recent years. Since the investment casting process is relatively complex and expensive compared with other casting processes (e.g., sand, permanent mold, etc.), total reliance on the old fashioned trial and error approach to selecting various process parameters is generally found to be time consuming and inadequate. Initially, a schematic flow of the main processes is provided; afterwards the main processes are discussed in more detailed manner with their manufacturing methods and product specifications.

These concepts are indispensable to introduce the discussion on the critical parameters for investment casting process and some proposal to implement a few new methods for quality assurance of the processes 
Citation: Bihari AK, Ramachandran M, Kumar V (2015) Effect of Process Parameters on Roughness and Hardness of Surface and Dimensional Accuracy of Lost Wax Process Casting. J Material Sci Eng 4: 175. doi:10.4172/2169-0022.1000175

and products. Finally a description of the economic impact of the critical manufacturing operations related to some specific case studies and possible goals have been identified.

\section{References}

1. Kumar $\vee$ Proprieter of Tara sree engineering and investment casting consultant. Awarded as emerging foundryman of India.

2. Cheng X, Sun XD, Yuan C, Green NR, Withey PA (2012) An investigation of a TiAlO based refractory slurry face coat system for the investment casting of Ti-Al alloys. Intermetallics 29: 61-69.

3. Patel JP, Patel CP, Patel UJ (2012) A review on various approach for process parameter optimization of fused deposition modeling and Taguchi approach optimization. International Journal of Engineering and Application 2: 361-365.

4. Pattnaik S, Karunakar B, Jha PK (2012) Developments in investment casting process: A review. Journal of Materials Processing Technology 212: 23322348.

5. Singh R (2013) Some investigations for small sized product fabrication with FDM for plastic component. Rapid Prototyping Journal 19: 58-63.

6. Singh R, Singh S (2013) Effect of process parameters on surface hardness, dimensional accuracy and surface roughness of investment cast components. Journal of Mechanical Science and Technology 27: 191-197.

7. Piwonka TS (1993) Modelling and Control of Casting. Welding and Advanced Solidification Processes VI. TMS Publications.
8. Amira S, Dube D, Tremblay R (2011) Method to determine hot permeability and strength of ceramic shell moulds. Journal of Materials Processing Technology 211: $1336-1340$

9. Jones S, Yuan C (2003) Advances in shell moulding for investment casting Journal of Materials Processing Technology 135: 258-265.

10. Hu C, Ou H, Zhao Z (2015) An alternative evaluation method for friction condition in cold forging by ring with boss compression test. Journal of Materials Processing Technology 224: 18-25.

11. Chen YS, Chuong LH (2014) Efficiency improvement of the highly accelerated life testing system by using multiple hammers. Journal of Mechanical Science and Technology 28: 4815-4831.

12. Singh R, Singh S, Mahajan V (2014) Investigations for Dimensional Accuracy of Investment Casting Process after Cycle Time Reduction by Advancements in Shell Moulding. Procedia Materials Science 6: 859-865.

13. Upadhya GK, Das S, Chandra U, Paul AJ (1995) Modelling the investment casting process: a novel approach for view factor calculations and defect prediction. Applied Mathematical Modelling 19: 354-362.

14. Xiaoxin Y, Tse Zion TH, Guoyi T, Guolin S (2014) Effect of electroplastic rolling on deformability, mechanical property and microstructure evolution of Ti-6Al-4V alloy strip. Materials Characterization 98: 147-161.

15. Xiaoxin Y, Tao L, Yongda Y, Haibo W, Guoyi T, et al. (2015) Enhanced grain refinement and microhardness of Ti-Al-V alloy by electropulsing ultrasonic shock. Journal of Alloys and Compounds 621: 66-70. 